\title{
THE SPECIFIC HEAT OF PLATINUM AT HIGH TEMPERATURES.
}

By Walter P. White.

$\mathrm{T}^{\mathrm{H}}$

E specific heats of metals at high temperatures are of special theoretic importance on account of the light they may throw on electronic theories, and among the metals platinum, for fairly evident reasons, is especially well adapted for an investigation of this kind. The present paper offers some new values of the specific heat of very pure platinum from $100^{\circ}$ to $1300^{\circ}$.

The apparatus and methods are the same as are to be described in presenting some work on the specific heats of certain silicates ${ }^{1-i n}$ fact, the two investigations were carried out together. Since the charge of platinum had about one third the heat capacity of the usual charge of silicate, the work with it was the measurement of a quantity one third as great, so that a precision a third as good, or to 3 per mille, would have seemed satisfactory, but in all but two cases this precision was exceeded. There is of course no reason to suspect a systematic error any greater than in the case of the silicates. Numerous and varied cross checks indicated that with them the systematic error did not reach 3 per mille in the worst instances. It is therefore probable, though of course not certain, that the discrepancy of .003 in the platinum values is the greatest error present.

Two samples of platinum were used. One was of Heraeus' purest thermoelement wire, drawn to $2 \mathrm{~mm}$. diameter, coiled to a convenient bulk, and annealed in an oxidizing flame at a temperature of about $800^{\circ}$. It was also abundantly annealed at $700^{\circ}$ in the course of the first specific heat determinations. This valuable wire, to avoid possibility of contamination, was not used above $700^{\circ}$. Above that temperature a lower grade of platinum was used, most of which was also from Heraeus and guaranteed not to contain over 0.005 of iridium. At $700^{\circ}$ this wire gave a result 0.00012 in 0.03 , or about 3 per mille, higher than the purest wire. It seemed best to diminish by this amount all the results with the lower grade wire, and to consider these as corrected for the variation from purity. The total value of this correction is only the maximum error of the observations. Moreover, it lowers the specific heat-a point of importance in comparing with some results obtained by others.

${ }^{1}$ Silicate Specific Heats, Second Series, Walter P. White, Am. J. Sci., 47, I, I9I9. 
Table I. gives the results. The differences in column 4 indicate a linear variation of the interval specific heat to well within the small experimental error, except between $100^{\circ}$ and $300^{\circ}$, where the difference is 0.0008 for the 200 degrees. The very accurate results of Gaede ${ }^{1}$ and Schlett ${ }^{2}$ show that below $100^{\circ}$ the variation reaches 0.0000065 calories per gram per degree (or 0.0013 for $200^{\circ}$ ) with a tendency to diminish; it may therefore very probably be .0008 below $300^{\circ}$. The present results at $100^{\circ}$ certainly show very satisfactory precision, and are also much less to be suspected of systematic error than those at the higher tempera-

TABLE I.

Specific Heat of Platinum.

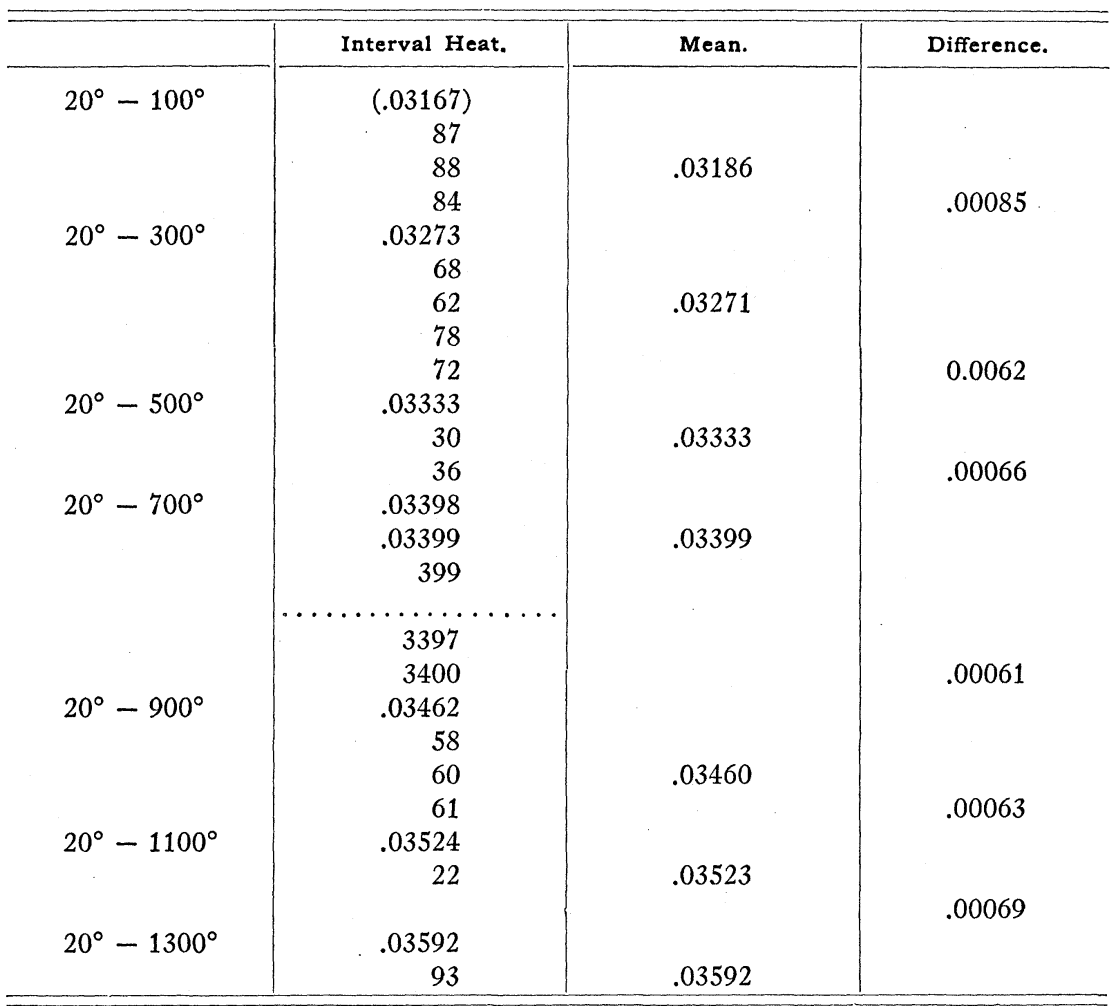

tures. The slight increase in the difference between $1100^{\circ}$ and $1300^{\circ}$ does not necessarily indicate any real departure from the linear relation. In my earlier results (1909) there was a decrease from $1300^{\circ}$ to $1500^{\circ}$, in which ${ }^{3}$ Koeningsberger found confirmation of a certain theory he had

1 Quoted by Magnus in the reference given later.

2 W. Schlett, Ann. d. Phys., 26, 20r, r9o8.

${ }^{3}$ Ueber den Anteil der freien Elektronen an der spezifische Wärme. J. Koenigsberger, Ber. Physik. Ges., I4, 278, I9r2. 
as to the variation with temperature of the number of electrons in metals. I have always suspected that the decrease was only experimental error, though I apparently did not bring that out clearly in the 1909 paper.

The results at $300^{\circ}$ and higher are well represented by the formula:

$$
.03175+0.0000032 \theta \text {, }
$$

which gives for the true specific heat ${ }^{1}$

$$
.031686+0.000064 \theta \text {. }
$$

The resulting value for the true atomic heat is:

$$
6.185+0.00125 \theta \text {. }
$$

This gives: at $500^{\circ}, 6.8 \mathrm{I}$; at $1300^{\circ}, 7.8 \mathrm{I}$. These values of course are for constant pressure. Values for constant volume can be obtained by the formula given in the silicate paper referred to:

$$
C_{p}-C_{v}=\frac{.02345(3 \alpha)^{2} \theta}{K d},
$$

where $d$ is density, $K$ compressibility $\left(K g\right.$ per $\left.\mathrm{cm}^{2}{ }^{2}\right), 3 \alpha$ the $c u b i c$ expansion coefficient, and the result is in calories per gram.

If we take compressibilities by linear extrapolation from Grüneisen's data, ${ }^{2}$ a process which gives, at $500^{\circ}, 900^{\circ}$ and $1300^{\circ}, .432, .465$, and $.498, \times 10^{-6}$, and derive both volume and expansion from the Holborn and Day formula: vol. $=\left(26.6 \theta+.004 \theta^{2}\right) \mathrm{ro}^{-6}$, expansion coefficient $=$ $(26.6+.008 \theta) 1^{-6}$, we get:

$$
\begin{aligned}
& C_{v} \quad A_{v} \quad \triangle C_{v} \\
& \text { At } 500^{\circ} \quad .03303 \quad 6.447 \\
& \begin{array}{lllll}
900^{\circ} & .0342 \mathrm{I} & 6.678 & .001 \mathrm{I} 8 \\
& & & .00086
\end{array} \\
& \begin{array}{lll}
\mathrm{I} 300^{\circ} & .03506 & 6.844
\end{array}
\end{aligned}
$$

$A_{v}$ is clearly above the kinetic theory value, 5.96 , and increases steadily at a rate somewhat less than 9 per mille per $100^{\circ}$. The increase is not linear, but the variation from linearity is not certainly greater than the possible errors. If the compress bility at high temperatures increases more than in proportion to the temperature, as seems not improbable from Grüneisen's results for lower melting metals, the variation might be considerably reduced. The data, also, are evidently not inconsistent with larger values at the higher temperatures. There is no reason to suppose that the specific heat at constant pressure really varies linearly, since

1 The first term differs from that in (I) because (I) is for intervals beginning with $20^{\circ}$ not $0^{\circ}$.

${ }^{2}$ E. Grüneisen, Ann. der Physik, 23, I264, I9ro. 
the contribution of expansion work to the specific heat does not. The only reasons for the linear formula are its simplicity, and the danger that a more elaborate expression might give an exaggerated idea of the supposed accuracy of the data.

\section{Comparisons with Previous Work.}

The results of Pouillet (1836) and Violle (1877), important and excellent in their day, differ materially from those obtained with modern resources, and do not seem to be longer of practical value. Plato ${ }^{1}$ appears to have been the first to get results which still seem satisfactory. He found .03369 and .03430 respectively for the intervals from room temperature to $600^{\circ}$ and $750^{\circ}$. My own earlier results, ${ }^{2}$ published in 1909 , gave $0.03198+0.0000034 \theta$, from $0^{\circ}$ to $\theta$, which is about 6 per mille too high. ${ }^{3}$ Corbino ${ }^{4}$ employed a very interesting method, based on the time required to heat a platinum wire by an electric current, and Fabaro ${ }^{5}$ confirmed his values by a different method embodying the same principle. One feature of Corbino's presentation is rather curious. His method gives only the change of specific heat with temperature. He quoted my I909 result at $500^{\circ}$ in order to assign absolute values for his own, but made no reference to any other of my results, or even to the fact that I had any others. He finds that $C_{v}$ increases 14 per mille per $100^{\circ}$, which brings his results into very good agreement with these here, if we consider that he only estimates the precision of any value as I per cent. A. Magnus, ${ }^{6}$ using a dropping method, measured from $500^{\circ}$ to $900^{\circ}$, that is, through one third the range of the present work, with a mean accidental error of 2 per mille, getting $0.031590+0.0000029234 \theta$ for the interval heat. These coefficients are respectively about 4 per mille and 6 per cent. smaller than those contained in this paper. He considered his results good to 5 per mille.

Up to $100^{\circ}$ determinations of the specific heat of platinum are more numerous. A good account of them is given by K. Schulz in the Fortschritte der Mineralogie for I9I2 and for 1913.

1 Erstarrungserscheinungen an anorganischen Salzen und Salzgemischen. W. Plato, Z. physik. Chem., 55, 735, 1906.

${ }^{2}$ Specific Heats of Silicates and Platinum. W. P. White. Am. J. Sci., 28, 342, I909.

${ }^{3}$ These determinations were only estimated as good to 5 per mille. They were made because we wanted the platinum values for use as a correction in silicate work with platinum containers. The use made of these results by others led us to think that more accurate ones would be acceptable.

${ }_{4}$ Theremo-kalorimetrische Untersuchungen am Platin. Physik. Z., I4, 9I5, I9I3.

5 Sul Calore Specifico del Platino a Elevati temperature. L. Fabaro, Nuovo Cim., 9, I23, I9I5.

${ }^{6}$ Die Spezifische Wärme des Platins und des Diamenten bei hohen Temperaturen, Ann. d. Physik, 48, 997, I915. 
The variations between different observers are very wide; values run from .03147 to .0328 for the interval $0^{\circ}$ to $100^{\circ}$. These divergences may be in part accounted for by the impurity of the platinum used by some of the earlier workers, and in part, by differences in the physical condition of the metal. Schlett ${ }^{1}$ finds very curious differences of this kind, though his experiments do not seem complete enough to lead to any general conclusions, except that there is a general tendency for the specific heat to vary with the specific volume. Gaede's probably very accurate results ${ }^{2}$ give .03175 for the interval $20^{\circ}-100^{\circ}$, which is below the present result of .03186, but scarcely differs from it by more than the observational errors. Battelli and Stracciati (1895) and Wigand (1907) are about a per cent. higher than the result given here. (Wigand gives two results differing a per cent. from each other.) Nearly everyone else is higher still. With the earlier workers this may sometimes be the result of impurity, but Jaeger and Diesselhorst, who had pure platinum, get two results respectively 2 per cent. and 3 per cent. above Gaede's. One may suspect that their apparatus, designed for different work, was not very well adapted for determining specific heats.

In I912 Koenigsberger, ${ }^{3}$ using my 1909 results, and also those of Kunz, ${ }^{4}$ calculated that the atomic heat at constant volume of platinum is above the Dulong and Petit value, and continues to increase with temperature. $\mathrm{He}$ very properly considered the question whether for a conclusion so important the data were sufficiently assured. The results which have since accumulated, for other metals as well as platinum, seem to leave no further doubt.

Corbino $^{5}$ also finds that tungsten shows an increase of specific heat above the theoretical 5.96, though his actual values differ considerably from the probably better ones of Worthing. ${ }^{6}$ Worthing finds, between I,200 abs. and 2,400 abs. generally lower absolute values than those of platinum, but a higher rate of increase, about $\mathrm{I} 3$ per mille per $100^{\circ}$.

\section{SUMMARY.}

The specific heat of platinum has been redetermined from $100^{\circ}$ to $1300^{\circ}$ with a precision estimated to be better than .3 per mille and with

\footnotetext{
${ }^{1}$ Loc. cit.

${ }^{2}$ Wolfgang Gaede, Ueber die Aenderung der spezifischen Waerme der Metalle mit der Temperature, Physik. Z., 4, I05, I902; Fortschr. Physik, 373.

${ }^{3}$ Loc. cit., p. 279.

${ }_{4}^{4}$ L. Kunz, Ann. d. Physik, I4, 309, 1904.

${ }^{5}$ Phys. Zeits., I3, 381, I9I2.

${ }^{6}$ Atomic Heats of Tungsten and of Carbon at Incandescent Temperatures. A. G. Worthing, Jour. Franklin Inst., 185, 707, I918; Phys. Rev., I2, 199, 1918.
} 
very satisfactory agreement with the results of Gaede at $100^{\circ}$ and with those of Plato, Corbino, Magnus, and Fabaro at higher temperatures. Most published results below $100^{\circ}$ appear to be I per cent. or more too high. The atomic heat of platinum at constant volume is, from $100^{\circ}$ up, above the value, 5.96, indicated by Dulong and Petit's law, and by the accepted kinetic theories of the solid state, and also increases regularly to $1300^{\circ}$, and probably beyond that.

Geophysical Laboratory,

Carnegie Institution of Washington,

WASHINGTON, D. C. 